\title{
COMPUTER-AIDED CONSTRUCTION AT DESIGNING REINFORCED CONCRETE COLUMNS AS PER EC
}

\author{
M. ZIELIŃSKA and K. GRĘBOWSKI* \\ Department of Structural Mechanics and Bridge Structures \\ Faculty of Civil and Environmental Engineering \\ Department of Technical Bases of Architectural Design \\ Faculty of Architecture \\ Gdansk University of Technology \\ ul. Narutowicza 11/12, 80-233 Gdansk, POLAND \\ E-mails: monika.zielinska@pg.gda.pl \\ karol.grebowski@pg.gda.pl
}

\begin{abstract}
The article presents the authors' computer program for designing and dimensioning columns in reinforced concrete structures taking into account phenomena affecting their behaviour and information referring to design as per EC. The computer program was developed with the use of $\mathrm{C}++$ programming language. The program guides the user through particular dimensioning stages: from introducing basic data such as dimensions, concrete class, reinforcing steel class and forces affecting the column, through calculating the creep coefficient taking into account the impact of imperfection depending on the support scheme and also the number of mating members at load shit, buckling length, to generating the interaction curve graph. The final result of calculations provides two dependence points calculated as per methods of nominal stiffness and nominal curvature. The location of those points relative to the limit curve determines whether the column load capacity is assured or has been exceeded. The content of the study describes in detail the operation of the computer program and the methodology and phenomena which are indispensable at designing axially and eccentrically the compressed members of reinforced concrete structures as per the European standards.
\end{abstract}

Key words: computer program, structure designing, reinforced concrete columns, Eurocodes.

\section{Introduction}

The notion of computer-aided construction includes designing and using advanced programs for effective and precise dimensioning of building structures, e.g. ,reinforced concrete columns which are one of the most popular types of structural components. They are usually a part of some structure, e.g., a frame. Those are compressed members designed to shift the load from the upper part of the structure (beams, plates) to lower structural systems or the foundations. Similar properties refer to a wall. The columns are components in which $h>4 b$, wider ones are rated among walls.

Among columns there are prefabricated columns or columns cast in place. They are usually in the shape of a square, rectangle or a circle. The columns are vertical single- or two-branch components. The reinforced concrete columns are divided into:

- non-spiral reinforced - reinforcement consists of longitudinal bars (the so-called main reinforcement) and links,

- spiral reinforced - instead of links spiral reinforcement is applied.

At designing reinforced concrete columns the following significant phenomena shall be taken into account:

\footnotetext{
* To whom correspondence should be addressed
} 
- impact of rheological processes,

- impact of imperfection,

- impact of the second order effects.

At dimensioning the column it is usually assumed that longitudinal reinforcement is not subject to any change at its entire length between the nodes. In advanced calculations one can take into account the possible mating of the column and the beam or the plate. However, it is more frequent that after the static analysis the columns are treated as isolated members. The static calculations of columns provide results in the form of: $\mathrm{M}_{\mathrm{Ed}}$ (bending moments), $\mathrm{N}_{\mathrm{Ed}}$ (axial forces) and $\mathrm{V}_{\mathrm{Ed}}$ (shearing forces). At the dimensioning the most important factors are bending moments and axial forces. At the dimensioning one shall calculate the volume of those parameters at both nodes of the column and determine the run at its entire length. For various load combinations numerous results are obtained. Selecting the most unfavourable situation is often not easy. Traditionally, for each node one takes into account the following sets of loads:

- $\mathrm{M}_{\mathrm{Ed} \text {,min }}$ and related force $\mathrm{N}_{\mathrm{Ed}}$,

- $\mathrm{M}_{\mathrm{Ed}, \max }$ and related force $\mathrm{N}_{\mathrm{Ed}}$,

- $\mathrm{N}_{\mathrm{Ed} \text {,max }}$ and related moment $\mathrm{M}_{\mathrm{Ed} \text {. }}$

The main part of the study involved developing the computer program destined for dimensioning the reinforced concrete columns. The program was developed in Visual C++ 2010 environment Express Edition by Microsoft and comprises four windows. The first one is used to introduce the column basic data: dimensions, concrete class, reinforced concrete class and forces affecting the column. The second part is used to calculate the creep coefficient. The subsequent window refers to the impact of imperfection depending on the support scheme, and also the number of components mating at load shift, and the effective length of the column. In the final, fourth part the graph of interaction curve is generated. In the same coordinate system there are additionally two dependence points $\mathrm{n}_{\mathrm{Ed}}$ on $\mathrm{m}_{\mathrm{Ed}}$ calculated as per methods of nominal stiffness and nominal curvature. The location of those points relative to the limit curve determines whether the column load capacity is assured or has been exceeded.

The content of the study defines in detail how the computer program operates. The study presents the program algorithm ,step by step”. Moreover, each aspect affecting the final result has been analysed herein (Ajdukiewicz, 2009; Łapko and Jensen, 2005; Łapko, 2001).

\section{Geometric imperfections}

Any inaccuracies in the performance of reinforced concrete components (geometrical deviations, i.e., shape and load location) are included through geometric imperfections. They shall be taken into consideration at ultimate limit state in regular and exceptional calculations. At the serviceability limit state they can be omitted. Deviations in the dimensions of cross-sections are usually included in the material coefficients. Therefore, they should not be included at the structure analysis.

The minimal eccentricity at calculating cross-sections affected by axial force with symmetrical reinforcement shall be assumed as the lower of two values: $e_{0}=\min \left\{\frac{h}{30}, 0.20\right\}$, where $h$ is the height of cross-section.

As per the Eurocode imperfections can be presented by deflection of the entire structure $\left(\theta_{i}\right)$. Those deflections generate horizontal components of vertical forces which generate additional bending moments (2.1).

$$
\begin{aligned}
& \theta_{i}=\theta_{0} \alpha_{h} \alpha_{m}, \\
& \theta_{0}=\frac{1}{200}
\end{aligned}
$$


$\alpha_{h}-$ reduction coefficient for member length/height (2.2)

$$
\alpha_{h}=\frac{2}{\sqrt{l}} \quad \frac{2}{3} \leq \alpha_{h} \leq 1,
$$

$\alpha_{m}-$ reduction coefficient for number of members (2.3)

$$
\alpha_{m}=\sqrt{0.5\left(1+\frac{1}{m}\right)} .
$$

The coefficient $m$ defined as the number of vertical components mating at load shift takes the value depending on three main cases:

- $m=1$ when the effect on isolated member is analysed,

- $m$ equals the number of vertical members taking part in shifting the horizontal force through the bracing system, when the effect on bracing system is analysed,

- $m$ takes the value of the number of vertical members in the storey(s) distributing the total horizontal force on the floor, when the effect on floor or roof diaphragms is analysed (Klempka, 2002; Kliszczewicz, 2008).

The effect of imperfections on isolated members can be analysed in two ways (Fig.1):

1) imperfections as eccentricity $e_{i}$ - applied for statically determinable members,

2) imperfections as shearing force $H_{i}$ (located in a point where maximal moment occurs) - applied for statically non-determinable members [6].
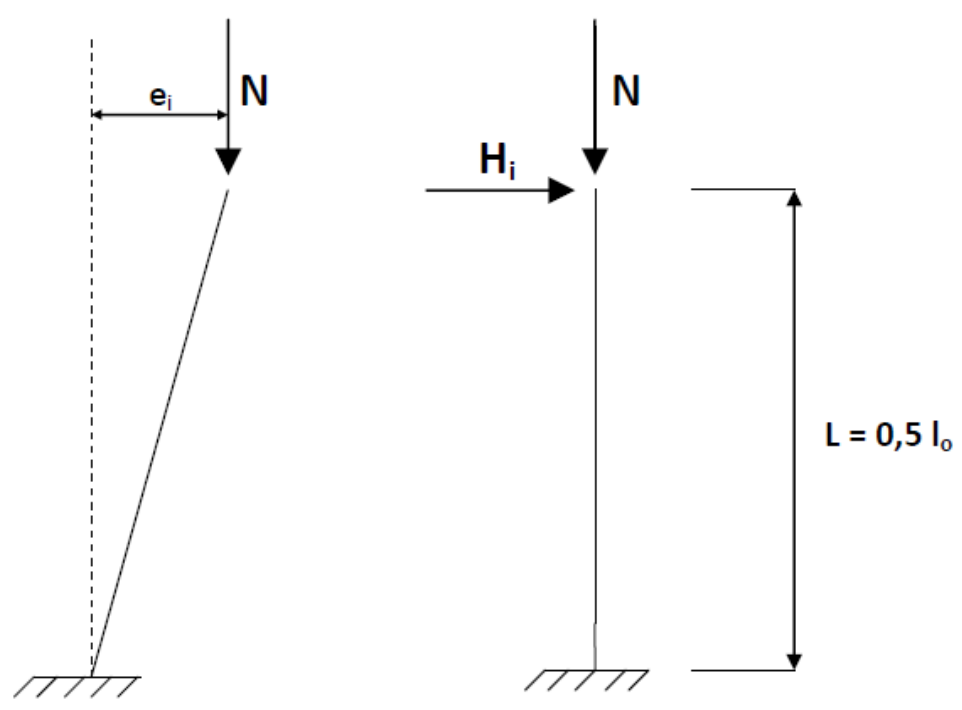

a) Braced member $e_{i}=0.5 \theta_{i} l_{0}$ $H_{i}=\theta_{i} N$ 
b) Unbraced member

$e_{i}=0.5 \theta_{i} l_{0}$

$H_{i}=2 \theta_{i} N$
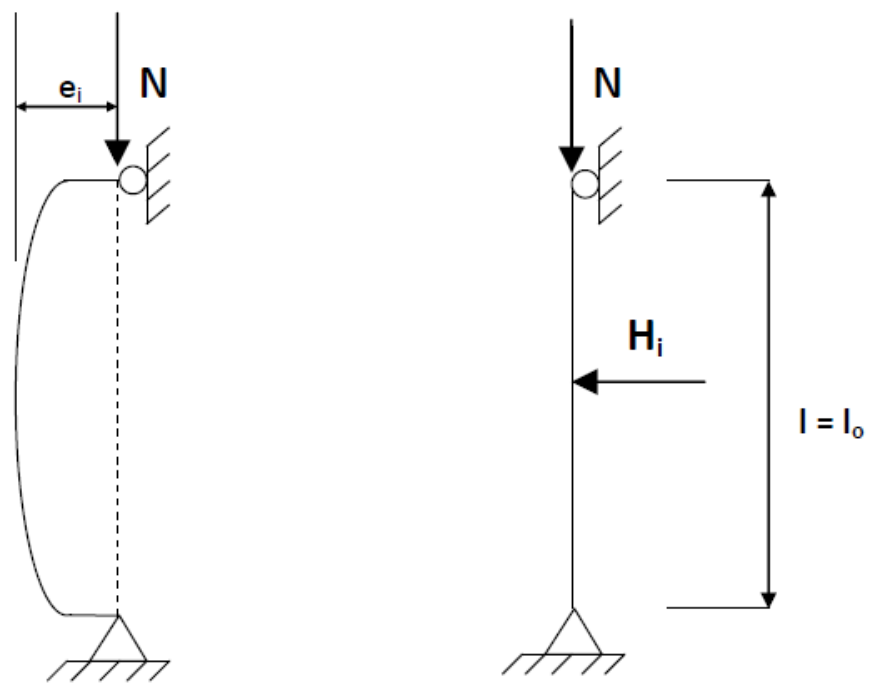

Fig.1. Example of the effect of imperfection on isolated member.

For isolated columns Eurocode allows applying simplifications, where $e_{i}=l_{0} / 400$.

Imperfections represented by the structure deflection $\left(\theta_{i}\right)$ can be expressed by load $H_{i}$ which in calculating the entire structures is analysed with other effects as per the following schemes (Fig.2)

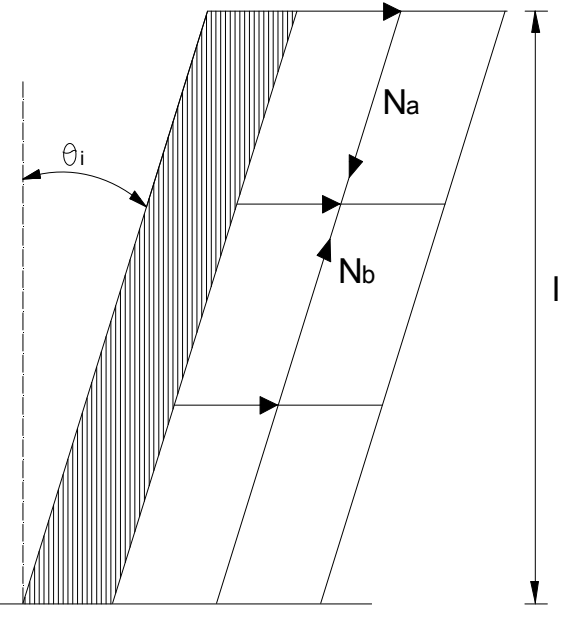

a) bracing system $H_{i}=\theta_{i}\left(N_{b}-N_{a}\right)$
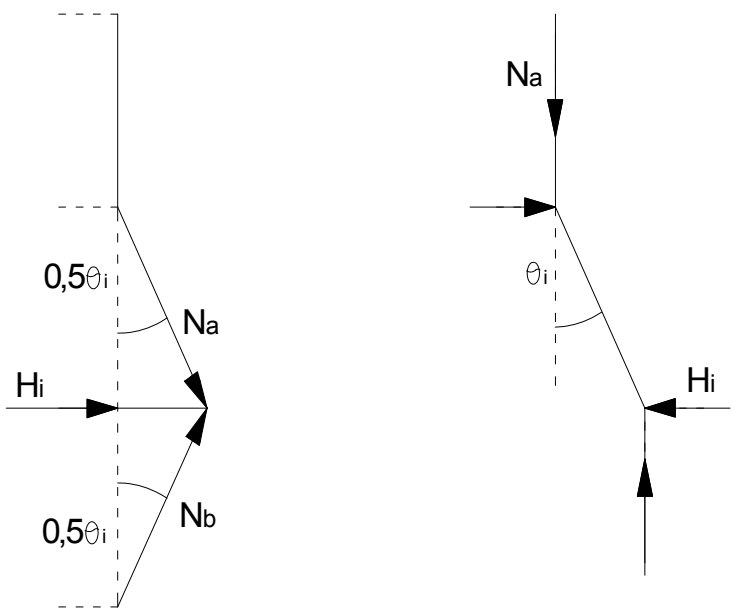

Fig.2. Examples of the effect of imperfections on the entire structure.

b) floor diaphragm c) roof diaphragm $H_{i}=0.5 \theta_{i}\left(N_{b}+N_{a}\right) \quad H_{i}=\theta_{i} N_{a}$ 


\begin{tabular}{|c|c|c|c|c|c|c|}
\hline 福 Reinforced columns : DAT & & & & & $=[$ & $\square \mathrm{x}$ \\
\hline Concrete class $[20 / 25$ & $\checkmark$ & \multicolumn{5}{|c|}{ Dimensions } \\
\hline$f_{c k}=20 \mathrm{MPa}$ & & \multicolumn{5}{|c|}{$\mathrm{b}=0,400 \hat{\mathrm{m}}$} \\
\hline$f_{c m}=28 \mathrm{MPa}$ & & \multicolumn{5}{|c|}{$\mathrm{h}=0,450 \stackrel{\Delta}{\mathbf{v}} \mathrm{m}$} \\
\hline$f_{c d}=14,29 \mathrm{MPa}$ & & \multicolumn{5}{|c|}{$a_{1}=0,050 \stackrel{\Delta}{v}$} \\
\hline \multirow{2}{*}{\multicolumn{2}{|c|}{$E_{\text {can }}=30 \mathrm{GPa}$}} & \multicolumn{5}{|c|}{$\mathrm{d}=0,400 \approx \mathrm{m}$} \\
\hline & & \multicolumn{5}{|c|}{$a_{2}=0,050 \hat{m}$} \\
\hline Steel class & & \multicolumn{5}{|c|}{ Force and moment } \\
\hline$f_{y x}=410 \hat{M} \mathrm{Ma}$ & & \multicolumn{2}{|c|}{ design } & \multicolumn{3}{|c|}{ characteristic } \\
\hline$\xi_{\text {lim }}=0,6667 \stackrel{\Delta}{v}$ & & $N_{E d}=$ & $500,00 \hat{\vee} \mathrm{kN}$ & $N_{i t}=$ & 370,37 参 & $\mathrm{kN}$ \\
\hline$E_{s}=200 \mathrm{GPa}$ & & $\mathrm{M}_{E \mathrm{~d}}=$ & $200,00 \hat{v} \mathrm{kNm}$ & $M_{11}=$ & 148,15 손 & $\mathrm{kNm}$ \\
\hline \multicolumn{7}{|l|}{$f_{y d}=356,52 \mathrm{MPa}$} \\
\hline & & Next & & & & \\
\hline
\end{tabular}

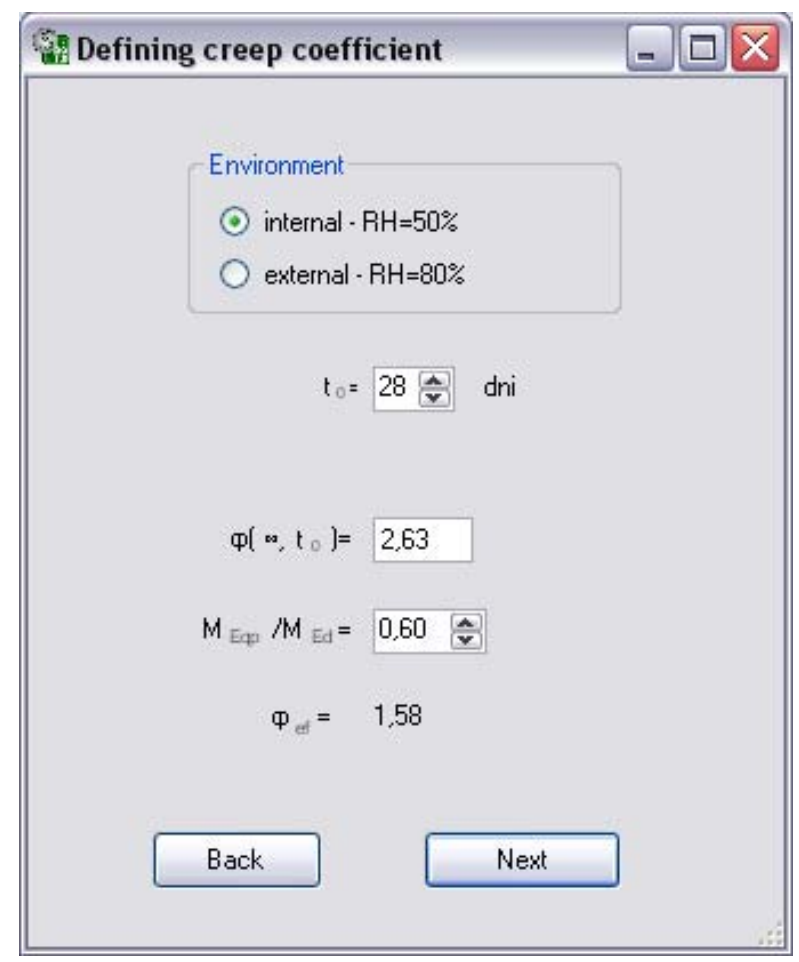




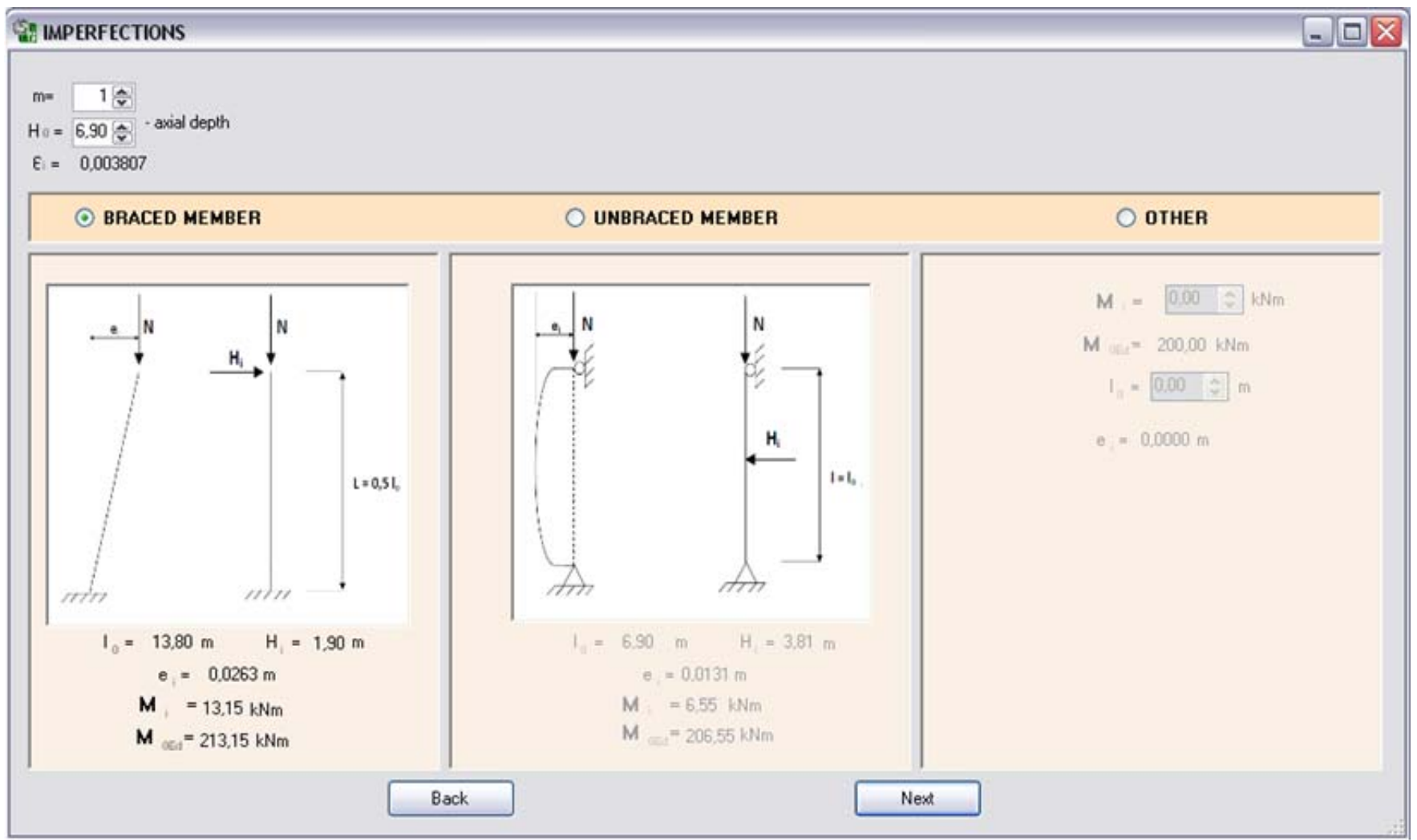

Fig.3. Example program windows - Introduction.

\section{Second order effects}

The second order effects involve the effects of additional impacts caused by structure deformations. They usually result from unintended bending moments or eccentricities. The said effects shall be taken into account when they have a significant impact on obtaining ULS in critical cross-sections or on the overall stability of the structure. It is allowed to omit the second order effects when they constitute less than $10 \%$ of the first order effects. The said statement is related to two particular limitations. The first refers to isolated members, whereas the other refers to the entire units and has not been discussed herein.

The second order effects can be included under methods of non-linear analysis with the use of relation $\sigma-\varepsilon$ or under simplified methods. The simplified methods include the method of nominal stiffness which leads to calculating the coefficient increasing the first order moment, and the method of nominal curvature which makes it possible to calculate the second order moment increasing the first order moment. Both methods involve replacing the analysis of the entire structure with the isolated member analysis. The impact of the other part of the structure is used for calculations through defining boundary conditions for an isolated column.

Taking into account the second order effects involves analysing the structure or its member in the deformed state. At that time, the vertical load generates an additional bending moment which is not included in the first order calculations.

The second order effects shall be included when their slenderness exceeds the limit value. The elements of small slenderness are the so-called thick members (3.1), (3.2).

$$
\lambda_{c}>\lambda_{\lim }
$$

where 
$\lambda$ - member slenderness,

$\lambda_{\lim }-$ limit slenderness.

$$
\lambda_{c}=\frac{l_{0}}{i}
$$

$l_{0}$ - effective length as per p. 3.2.,

$i$ - radius of gyration of the uncracked section without reinforcement.

The rectangle radius of gyration amounts to Eq.(3.3)

$$
i=\frac{h}{2 \sqrt{3}}
$$

$h-$ rectangular section depth.

of Eq.(3.4)

Consequently, it leads to simplifying the formula for slenderness of rectangular columns in the form

$$
\lambda_{c}=3.464 \frac{l_{0}}{h} .
$$

The Eurocode fails to limit the maximal level of slenderness; however, at significant slenderness ratios it seems advisable to verify the reliability of calculations Eqs (3.5)-(3.12).

$$
\lambda_{\lim }=\frac{20 \cdot A \cdot B \cdot C}{\sqrt{n}}
$$

where

$n$-relative axial force,

$$
n=\frac{N_{E d}}{A_{c} \cdot f_{c d}}
$$

$A$ - coefficient dependent on creep,

if $\varphi_{e f}$ value is unknown, it can be assumed that $A=0.7$.

$$
A=\frac{1}{1+0.2 \cdot \varphi_{e f}}
$$

$B$ - coefficient dependent on reinforcement intensity,

if $\omega$ value is unknown, it can be assumed that $B=1.1$.

$\omega$ - reinforcement intensity,

$A_{s}-$ total reinforcement area,

$$
\begin{aligned}
& B=\sqrt{1+2 \omega}, \\
& \omega=\frac{A_{s} f_{y d}}{A_{c} f_{c d}}
\end{aligned}
$$


$C$ - coefficient dependent on the first order end moments, at

$$
\left|M_{02}\right| \geq\left|M_{01}\right|,
$$

if $r_{m}$ value is unknown, it can be assumed that $C=0,7$.

$$
\begin{aligned}
& C=1.7-r_{m}, \\
& r_{m}=\frac{M_{01}}{M_{02}} .
\end{aligned}
$$

The coefficient $C$ depends on the moments graph along the length of the analysed member and on the scope of bracing. If $M_{01}$ and $M_{02}$ moments give tension on the same side, the coefficient $r_{m}$ takes a positive value and $C \leq 1.7$, in other cases it takes negative value and then $C>1.7$ (Figs 4, 5).

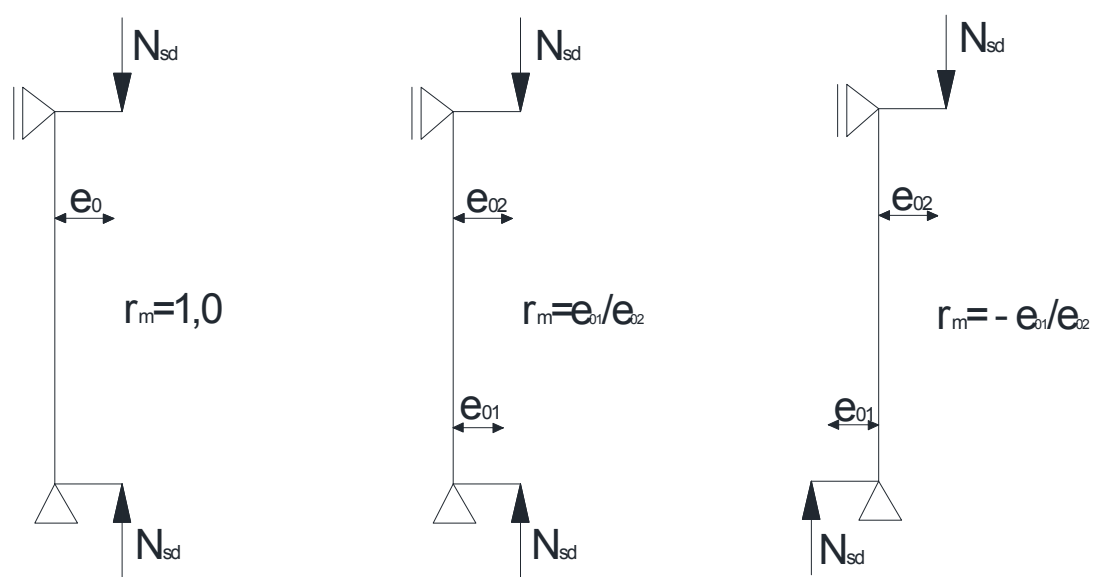

Fig.4. Calculation of $r_{m}$ coefficient depending on the moments graph.
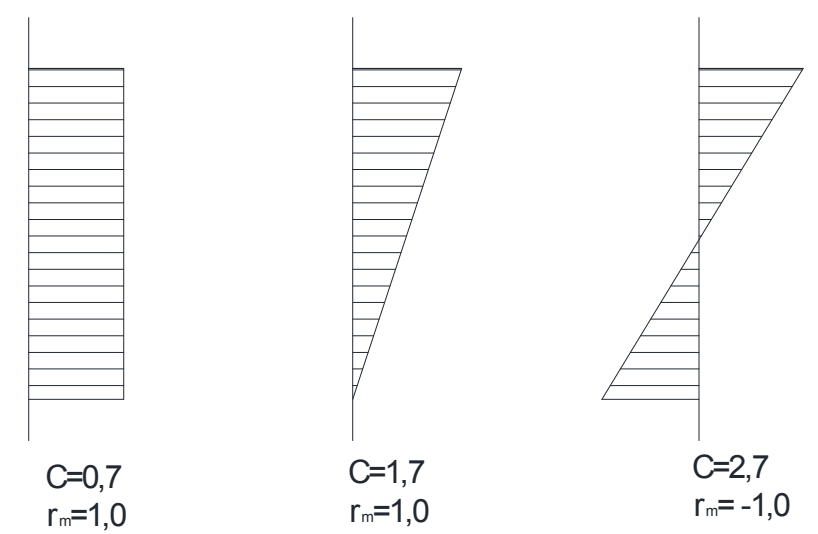

Fig.5. Defining $C$ coefficient depending on the moments graph . 
In braced structures $C$ can be assumed depending on the moments graph:

- ternary graph: $C=1.7$,

- rectangular graph: $C=0.7$,

- graph variable as per sign: $C=2.7$.

In unbraced structures the value of $C=1.7$.

The effective lengths of isolated members depend on the support scheme and the actual length. They are determined under buckling mode as per the following examples (Figs 6, 7, 8)

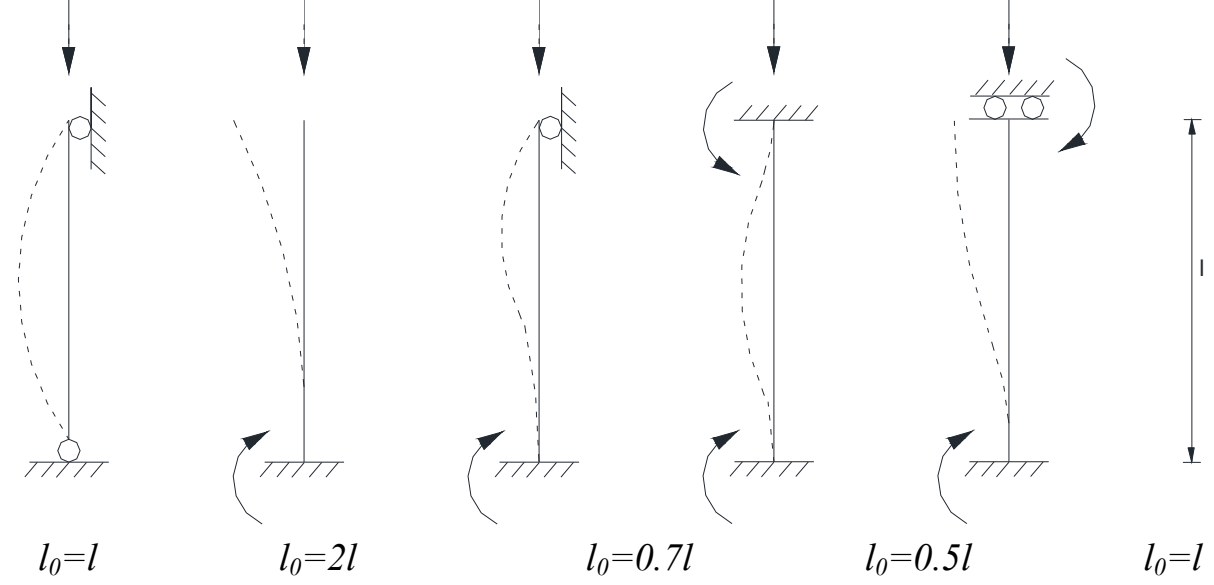

Fig.6. Buckling modes of isolated members and their effective lengths.

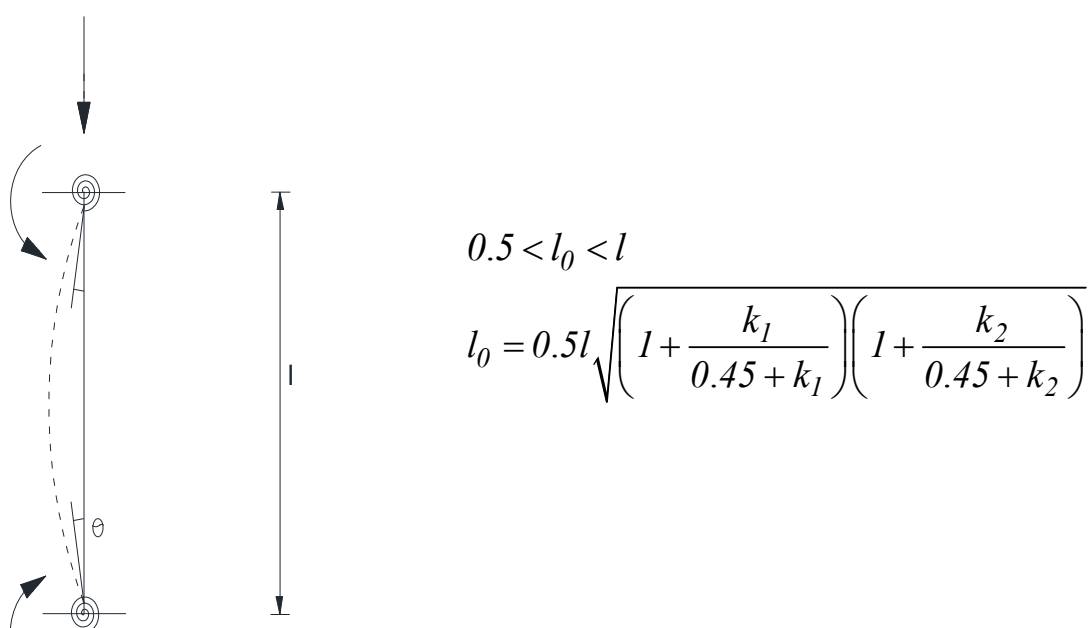

Fig.7. Effective length of braced member at elastic fastening. 


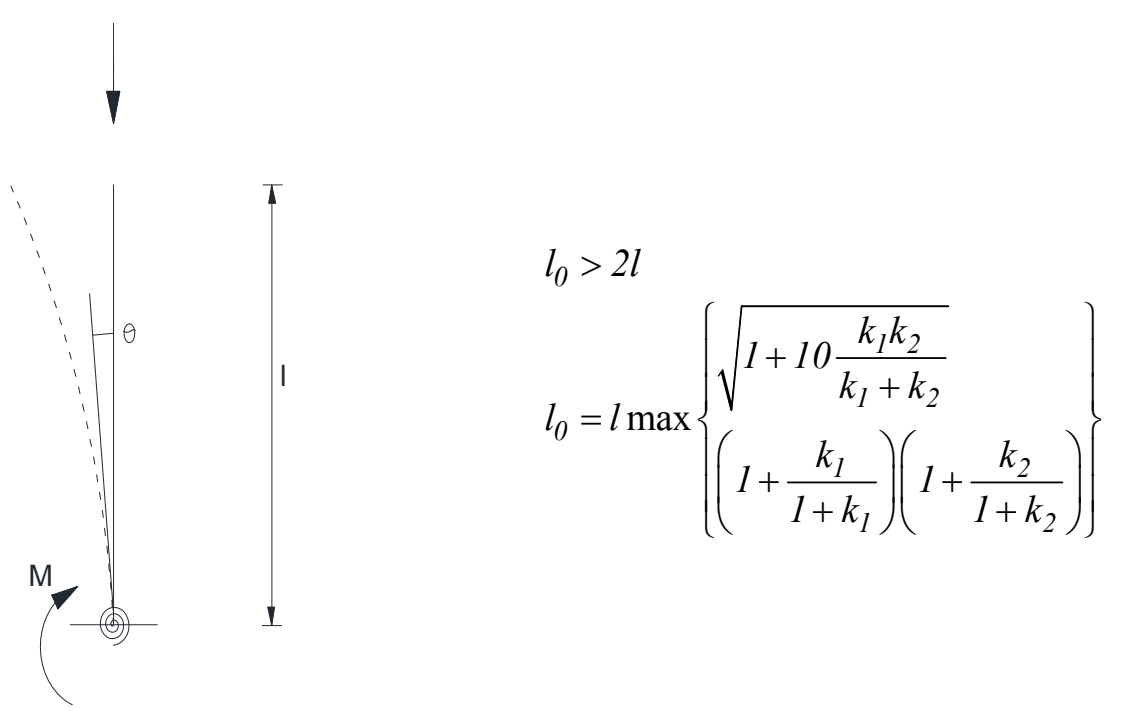

Fig.8. Effective length of unbraced member at elastic fastening.

where

$k_{1}, k_{2}$ - rotational flexibility at the point connecting the column with the restraining member (3.13).

$$
k=\frac{\theta}{M} \frac{E I}{l}
$$

$\theta$ - rotation of restraining members for $M$ moment,

$E I-$ flexural stiffness,

$l$ - clear height.

The flexibility of members takes 0 value at rigid restraint, but approaches infinity at no restraint at all. As per the Eurocode it is recommended to assume flexibilities $k$ as a value of at least 0,1 since there is no full rigid restraint (Kamiński, 1996; ....).

If a member fails to refer to any of the above mentioned examples, the effective length is calculated as follows (3.14)

$$
l_{0}=\pi \sqrt{\frac{E I}{N_{E}}}
$$

$N_{B}$ - buckling load for $E I$ stiffness.

\section{Methodology for dimensioning reinforced concrete columns as per EC}

The general method is based on non-linear stress-strain relations of steel and concrete. During the application of the said method one shall take into account the impact of creep. It is also recommended to consider the effect of cracking on the stiffness of members.

The said method requires the use of computer methods since they make it possible to calculate the stiffness and displacements of structure at gradual superposition of loads. Thanks to the said data it is possible to calculate further the dependent internal forces. The application of the said method is based on a precise determination of material properties, shape of the structure, distribution of reinforcement, influencing 
loads and their history, but also the course of phenomena related to shrinkage and creep. While designing the structure the actual evaluation of all listed factors is nearly impossible, therefore the said method is used mainly for scientific works.

It is well-grounded and possible to apply simplifications which involve the assumption that the stiffness of members is constant along its length. Thanks to them it is possible to apply calculations under algorithms for elastic geometrically non-linear structures. The bending moments calculated in the said manner in critical cross-sections are increased by moments induced by structure displacements (Pędziwiatr, 2010).

\section{NOMINAL STIFFNESS METHOD}

The second order moment calculated as per nominal stiffness method involves calculating the coefficient increasing the first order moment as per formula (4.1)

$$
M_{E d}=M_{O E d}\left(1+\frac{\beta}{\frac{N_{E}}{N_{E D}}-1}\right)
$$

where: $M_{O E d}$ - the first order moment, $N_{E d}$ - design value of axial force, $N_{B}$ - critical force due to buckling, calculated as per classic Euler's formula, with the assumption that stiffness is equal to nominal, expressed by formula (4.2)

$$
N_{B}=\pi^{2} \frac{E I}{l_{0}^{2}}
$$

$\beta$ - coefficient dependent on the distribution of the first and the second order moments (4.3)

$$
\beta=\frac{\pi^{2}}{c_{0}}
$$

$c_{0}$ - coefficient dependent on the distribution of the first order moment: $c_{0}=8$ rectangular graph, $c_{0}=9.6$ parabolic graph,

$c_{0}=12$ symmetrical ternary graph.

If there is a different type of graph, $\beta$ coefficient is assumed as $1.00(4.4)$.

$$
E I=K_{c} E_{c d} I_{c}+K_{s} E_{s} I_{s}
$$

$E_{c d}$ - design value of modulus of concrete elasticity,

\section{NOMINAL CURVATURE METHOD}

The second order moment calculated as per the method of nominal curvature involves increasing the first order moment as per the following formulae (4.15), (4.16), (4.17)

$$
M_{E d}=M_{0 E d}+M_{2}
$$

$M_{O E d}$ - the first order moment with the effect of imperfections,

$M_{2}$ - nominal second order moment,

$$
M_{2}=N_{E d} e_{2}
$$

$N_{E d}$ - design value of axial force,

$e_{2}-$ deflection as per the following formulae (Fig.9)

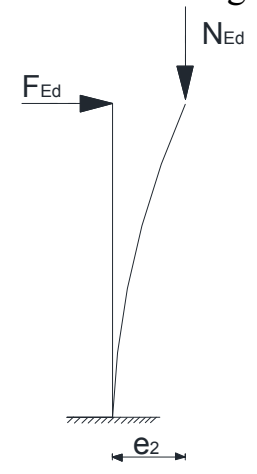

Fig.9. Scheme of column model.

$$
e_{2}=\frac{1}{r} \frac{l_{0}^{2}}{c}
$$

$1 / r$ - curvature,

$l_{0}$ - effective length,

$c$ - coefficient dependent on curvature distribution (for constant cross section assumed as $c=10$, if additionally the first order moment is constant, then to $c=8)(4.18)$. 
$I_{c}$ - second moment of area of concrete section,

$E_{s}$ - design value of modulus of reinforcing steel elasticity,

$I_{s}$ - second moment of area of reinforcement relative to concrete area centre of gravity,

$K_{c}-$ coefficient dependent on the effect of cracking, concrete creep, etc.,

$K_{s}-$ coefficient dependent on the level of reinforcement.

If the reinforcement ratio $\rho \geq 0.002, K_{s}$ and $K_{c}$ coefficients take the form of Eqs (4.5)-(4.10)

$$
\begin{aligned}
& K_{s}=1.0, \\
& K_{c}=\frac{k_{1} k_{2}}{1+\varphi_{e f}}, \\
& k_{1}=\sqrt{\frac{f_{c k}}{20}}, \\
& k_{2}=n \frac{\lambda}{170} \leq 0.20, \\
& n=\frac{N_{E d}}{A_{c} f_{c d}}, \\
& k_{2}=0.30 n
\end{aligned}
$$

$\rho$ - reinforcement ratio,

$\varphi_{e f}$ - effective creep coefficient,

$n$ - relative axial force,

$k_{1}-$ coefficient dependent on concrete strength class,

$k_{2}$ - coefficient dependent on axial force and slenderness.

If the reinforcement ratio $\rho \geq 0.01$, then $K_{s}$ and $K_{c}$ coefficients are calculated as per the following formulas (4.11), (4.12)

$$
\begin{aligned}
& K_{s}=0, \\
& K_{c}=\frac{0.3}{1+0.5 \varphi_{e f}} .
\end{aligned}
$$

In statically indeterminable structures the effects of creep and cracking of compression members and adjacent members shall be taken into

$$
\frac{1}{r}=K_{r} K_{\varphi} \frac{1}{r_{0}}
$$

$K_{r}$ - correction coefficient depending on axial load, $K_{\varphi}$-coefficient dependant on creep.

Curvature corresponding to reinforcement yield load $\left(1 / r_{0}\right)$ is determined under Fig.3.7. as per formula (4.19) (Fig.10)

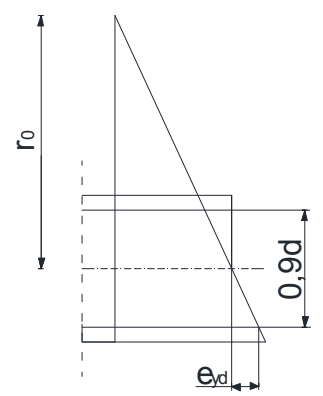

Fig.10. Defining section curvature.

$$
\frac{1}{r_{0}}=\frac{\varepsilon_{y d}}{0.45 d}
$$

$d$ - effective depth of cross-section.

If reinforcement is not concentrated on opposite section sides and its part is distributed parallel to the plane of bending, $d$ value is defined as follows (4.20)

$$
d=0.5 h+i_{s}
$$

$i_{s}$ - radius of gyration of total reinforcement.

The coefficient $K_{r}$ is calculated as per Fig.11 under the following formula (4.21)-(4.24) (Fig.11)

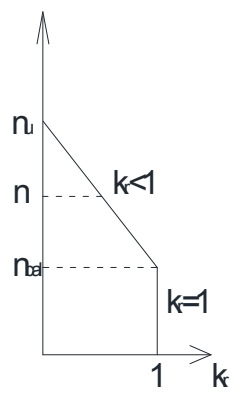

Fig.11. Defining $K_{r}$ coefficient. 
account. Under the following the Eurocode formula recommends to assume that sections are fully cracked and the elasticity modulus takes the effective value (4.13).

$$
E_{c d, e f f}=\frac{E_{c d}}{1+\varphi_{e f}}
$$

$E_{c d}-$ design value of elasticity modulus,

For members without transverse load, differing first order end moments $\left(M_{01}\right.$ and $\left.M_{02}\right)$ may be replaced by equivalent moments as per the following formula (4.14)

$$
M_{0 e}=0.6 M_{01}+0.4 M_{02} \geq 0.4 M_{02}
$$

where: $\left|M_{02}\right| \geq\left|M_{01}\right|$.

$$
\begin{aligned}
& K_{r}=\frac{n_{u}-n}{n_{u}-n_{b a l}} \leq 1.0, \\
& n_{u}=1+\omega, \\
& \omega=\frac{A_{s} f_{y d}}{A_{c} f_{c d}} \\
& n=\frac{N_{E d}}{A_{c} f_{c d}}
\end{aligned}
$$

$n$ - relative axial force,

$N_{E d}-$ design value of axial force,

$n_{\text {bal }}-n$ value at maximum moment resistance; it can be assumed that $n_{b a l}=0.4$ (4.25), (4.26).

$$
\begin{aligned}
& K_{\varphi}=1+\varphi_{e f} \beta, \\
& \beta=\left(0.35+\frac{f_{c k}}{200}-\frac{\lambda_{c}}{150}\right) .
\end{aligned}
$$

The principle of checking the resistance under limit curve is presented as follows (Fig.12)

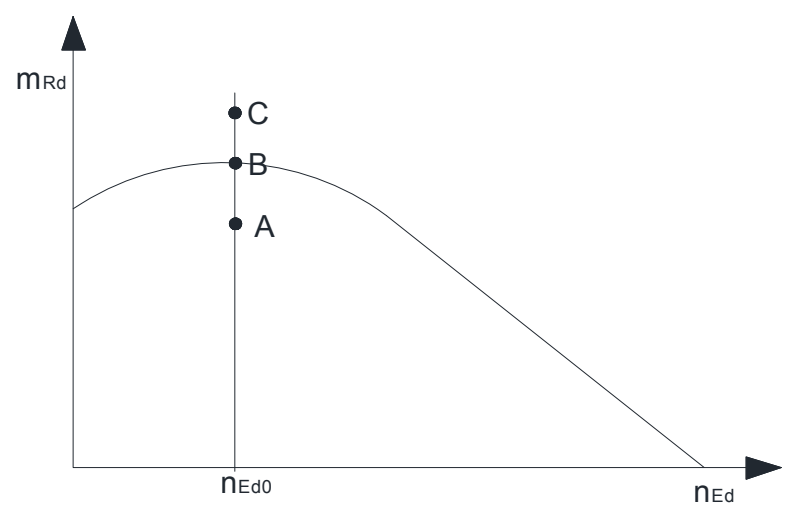

Fig.12. Resistance limit curve.

For a particular value of $n_{E d}=n_{E d 0}$ point:

$\circ \mathrm{A}-$ defines the bending moment which satisfies the requirements concerning the resistance standard, is situated under interaction curve,

- $\mathrm{B}-$ is equal to the limit moment, is situated on interaction curve,

- $\quad$ C - fails to satisfy the standard requirements concerning the resistance, is situated below the limit curve (Pyrak, 2001; EN 1992-1-1).

The coordinates of the points are calculated as per the formula (4.27)

$$
n_{E d}=\frac{N_{E d}}{b d f_{c d}} \quad m_{R d}=\frac{M_{E d}}{b d^{2} f_{c d}} .
$$

\section{Algorithm of program operation}

The algorithm of calculations and program operation are presented below step by step (Figs 13, 14, 15) 


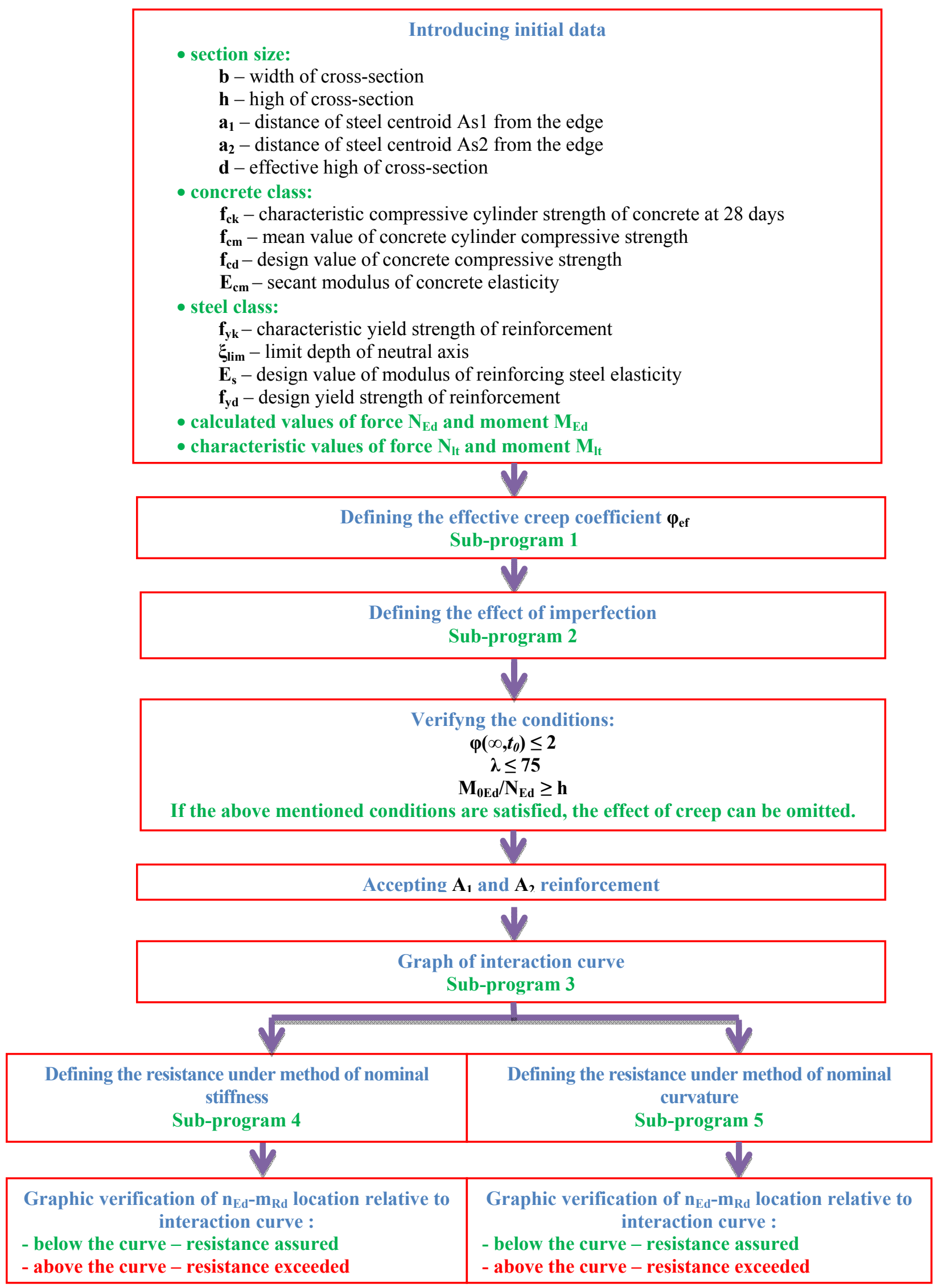




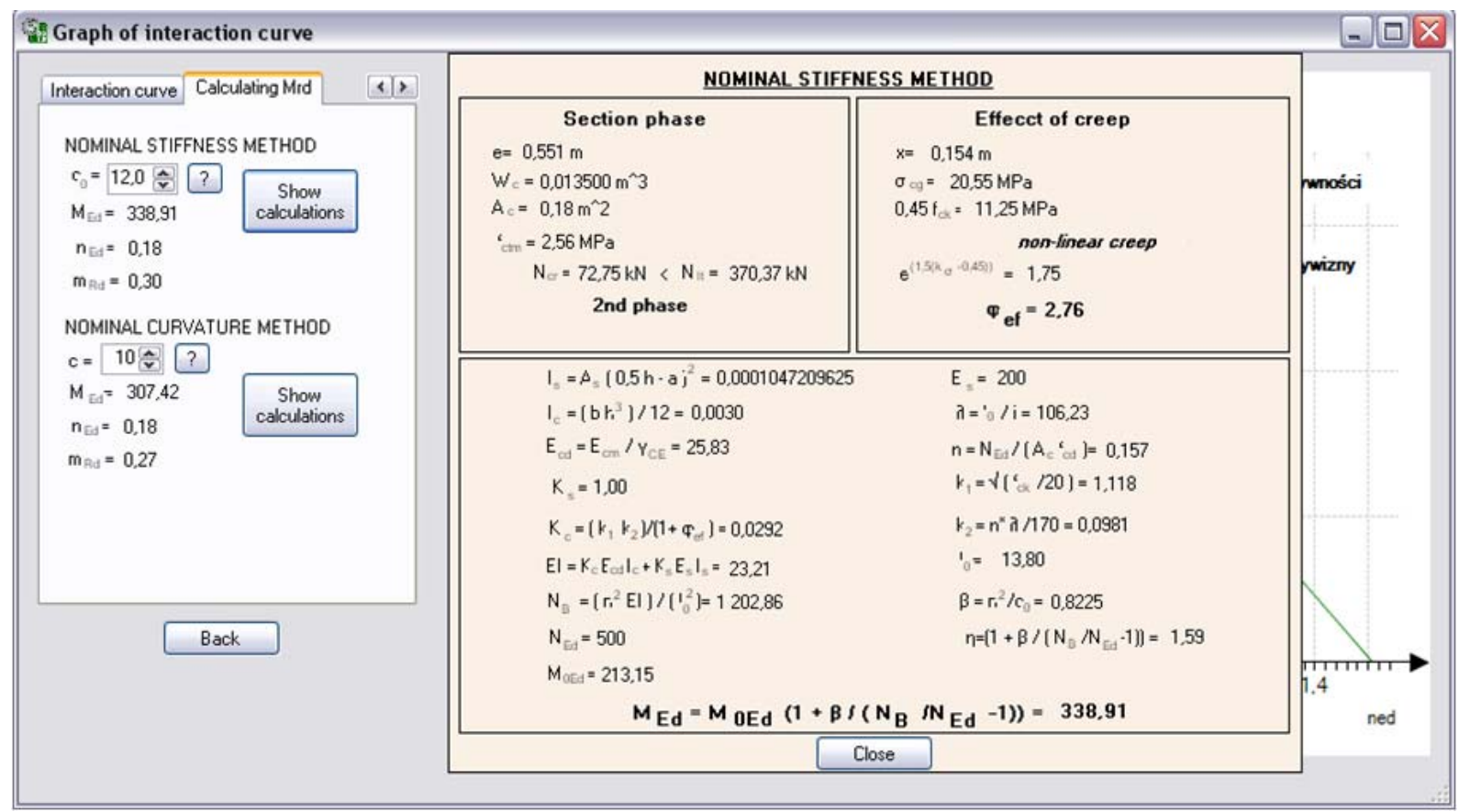

Fig.13. View of example program windows - Nominal stiffness method.

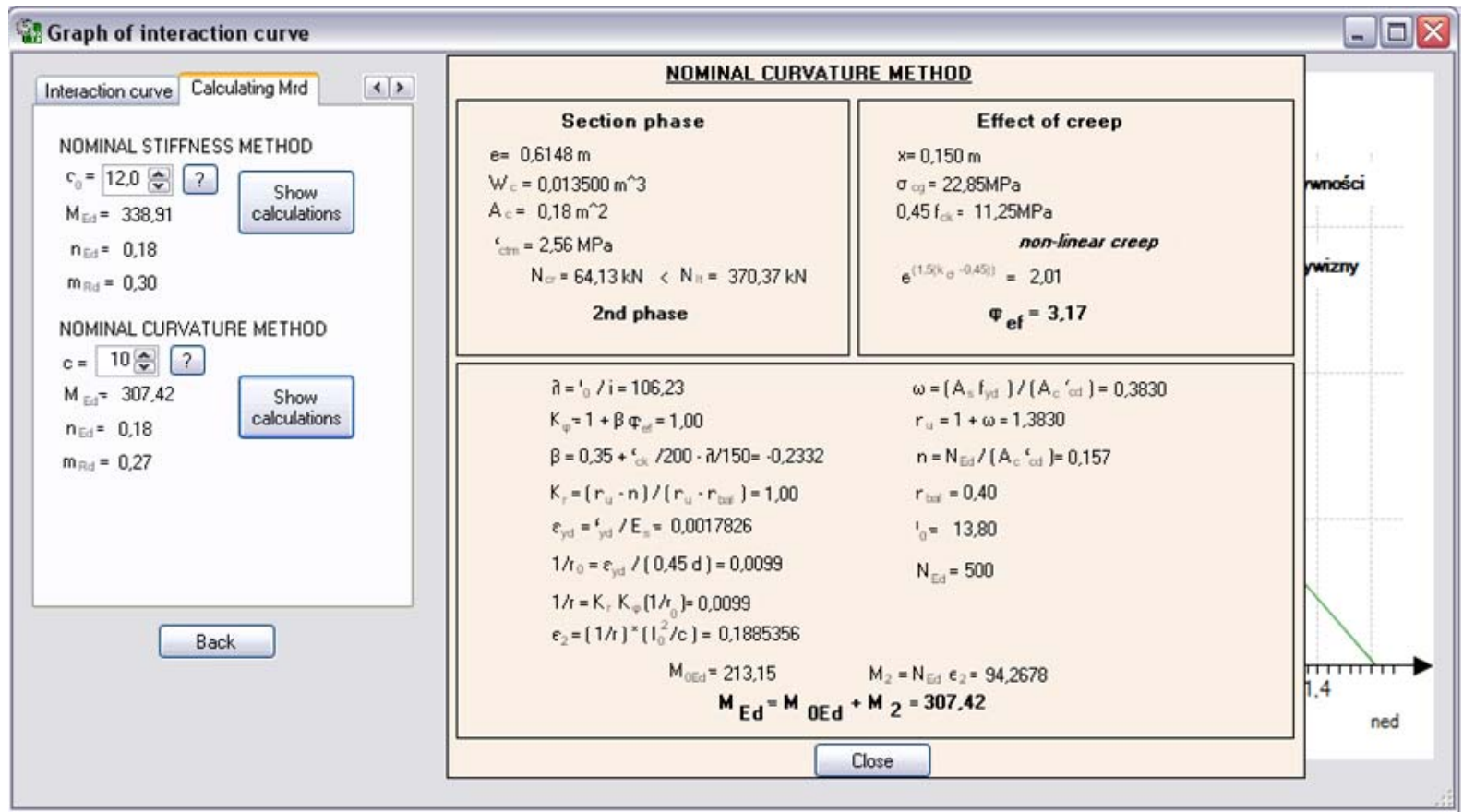

Fig.14. View of example program windows - Nominal curature method. 


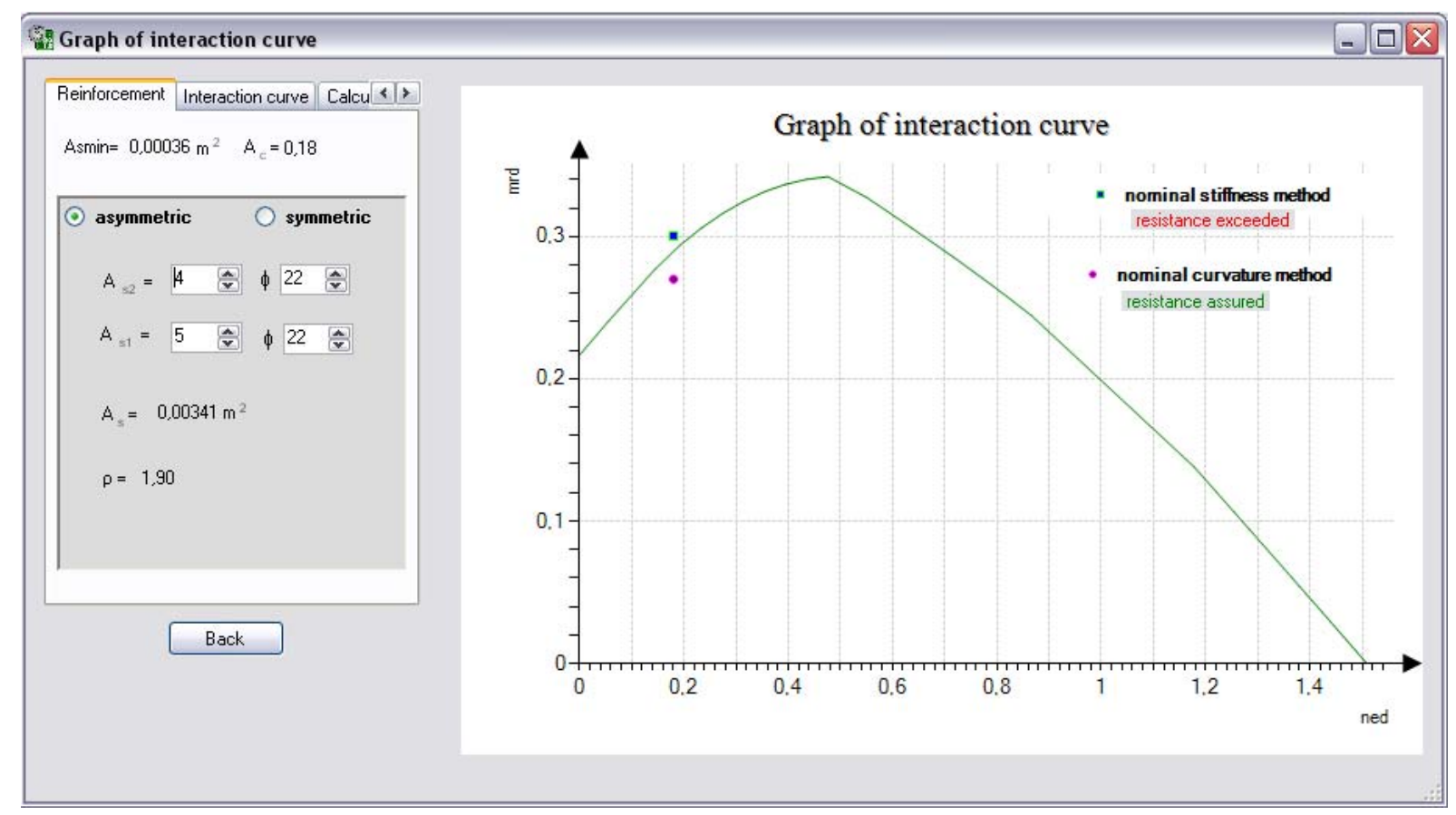

Fig.15. View of example program windows - Graph of interaction curve.

In order to verify the correct operation of the computer program manual calculations were performed as a comparison (Fig.16)

a) Nominal stiffness method:

- manual calculation $\mathrm{M}_{\mathrm{Ed}}=338.90[\mathrm{kNm}]$

- program calculations $\mathrm{M}_{\mathrm{Ed}}=338.91[\mathrm{kNm}]$

b) Nominal curvature method:

- manual calculation $\mathrm{M}_{\mathrm{Ed}}=307.40[\mathrm{kNm}]$

- program calculations $\mathrm{M}_{\mathrm{Ed}}=307.42[\mathrm{kNm}]$
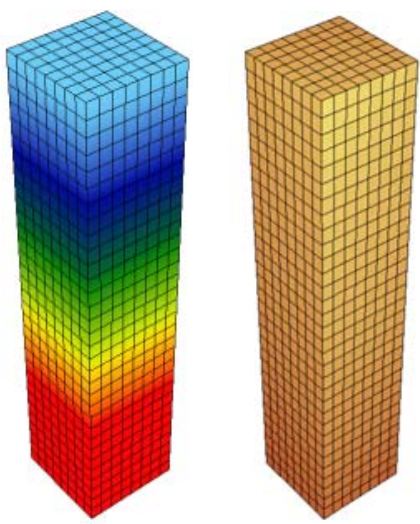

Fig.16. Animation of reinforced concrete columns behaviour.

\section{Conclusions}

The study aimed at presenting the authors' computer program for designing and dimensioning columns in reinforced concrete structures taking into account phenomena affecting their behaviour and information related to design as per EC.

Under the conducted programming and calculations the following conclusions were formulated:

1) The correctness of the program was verified by comparing the results with the manually performed results. 
2) The difference between the results obtained during manual calculations and the results obtained in the computer program amounts to $0.01 \%$.

3) The course of limit curve is affected by: the size of the column cross-section, concrete and steel class, area of reinforcement and distance of reinforcement centre of gravity relative to the reinforcement area.

4) Significant differences between the results as per the nominal curvature and nominal stiffness methods are obtained at small area of reinforcement.

5) Thanks to the computer program everyone can design reinforced concrete columns as per EC in a simple, quick and precise manner.

6) The computer program is a perfect instrument for architects since it is very intuitive and makes it possible, quickly and without extensive knowledge on the structure behaviour, to dimension the structure members.

\section{Nomenclature}

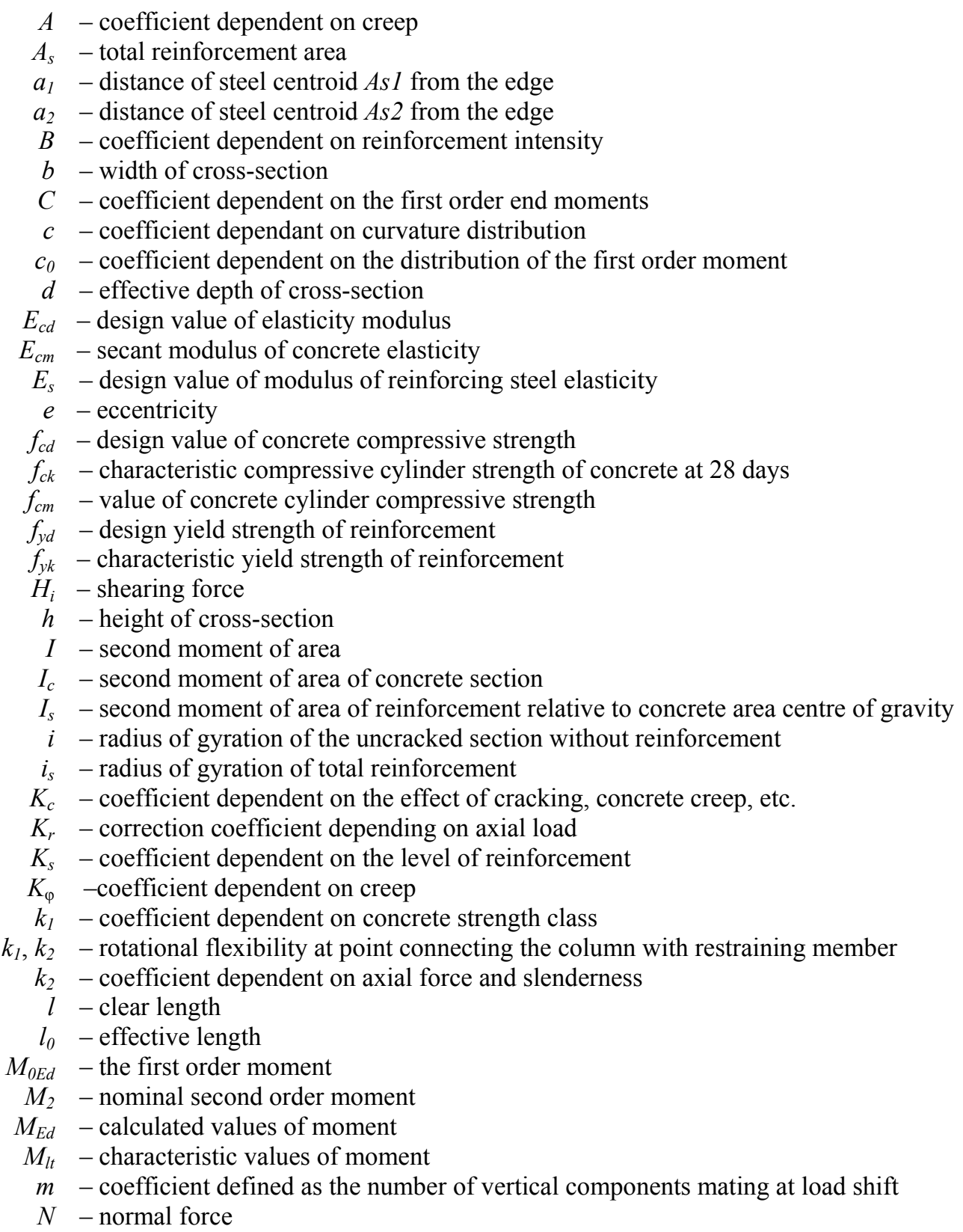




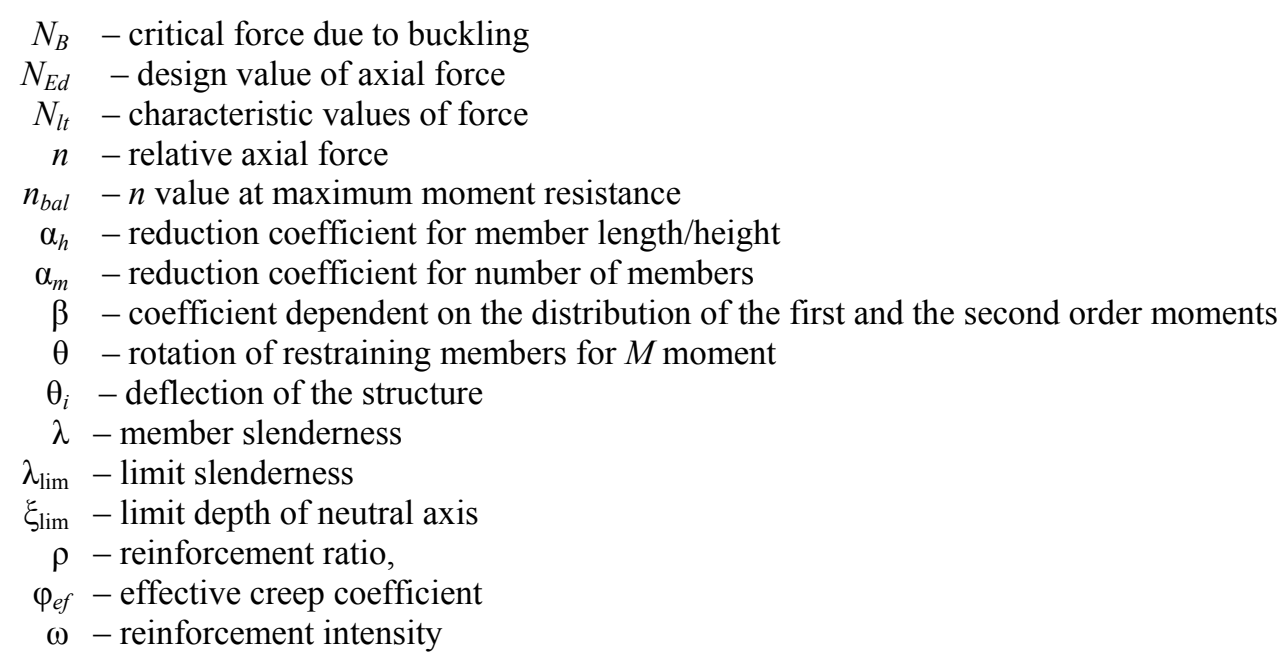

\section{References}

Ajdukiewicz A. (2009): A handy shortcut for designers of reinforced concrete structures. - Association of Cement Producers, Krakow.

Basis of structural design of reinforced concrete and prestressed concrete according to Eurocode 2. - Lower Silesia Educational Publishers, Wroclaw, 2006.

Comment to PN-B-03264: 2002 "Concrete structures, reinforced concrete and prestressed". - Building Research Institute, Warsaw 2005.

EN 1992-1-1, Eurocode 2: Design of concrete structures - Part 1-1 : General rules and rules for buildings.

Kamiński M. (ed.) (1996): Fundamentals of design of reinforced concrete structures according to Eurocode 2. - PWN, Warsaw-Wroclaw.

Klempka K. (2002): Calculation of load capacity of reinforced concrete slender compression elements. - Warsaw.

Kliszczewicz R. (2008): Concrete Structures. The calculation of reinforced concrete elements in the ultimate limit states and the use of PN-B-03264: 2002. - Publishing, Gliwice.

Łapko A. (2001): Design of reinforced concrete structures. - Arkady, Warsaw.

Łapko A. and Jensen B.Ch. (2005): Fundamentals of design and algorithms for the calculation of reinforced concrete structures. - Arkady, Warszawa.

Pędziwiatr J. (2010): Introduction to the design of reinforced concrete structures according to EN 1992-1-1: 2008. Lower Silesia Educational Publishers, Wrocław.

Pyrak S. (2001): Concrete structures. - School and Pedagogical Publishing House, Warsaw.

Received: August 30, 2014

Revised: November 12, 2014 